Helgoländer wiss. Meeresunters. 17, 518-522 (1968)

\title{
International Symposium "Biological and hydrographical problems of water pollution in the North Sea and adjacent waters": Closing address
}

\author{
OTTO KINNE
}

Biologische Anstalt Helgoland, Zentrale, Hamburg 50

Ladies and gentlemen

Dear colleagues and friends

Our International Symposium 1967 on "Biological and hydrographical problems of water pollution in the North Sea and adjacent waters" has come to a conclusion. I do hope that at least some of your expectations have been met and that this Symposium has provided a useful forum for the presentation and discussion of our present knowledge on North Sea pollution.

Marine water pollution may be defined as "Human activities causing negative effects on marine life, human health, resources or amenities". Taken in this sense, marine water pollution has rapidly become a problem of grave concern in the North Sea, because of the increasing role of this shallow secondary sea as a dumping area for industrial waste products. Papers and discussions presented at this Symposium have conveyed a sense of urgency in regard to dealing with this problem; they have also made it clear that marine sciences will have to go a long way to provide solutions to this problem acceptable to all groups of the human society concerned; they have demonstrated that pollution research is a rather new domain for many of us - all too suddenly confronted with its dangerous acuteness - and that it is characterized by an unexpectedly high degree of complexity. No wonder, therefore, that some of the papers had a rather preliminary character or were devoted to quite restricted aspects.

Nevertheless, this international meeting has provided what may be considered a first critical assessment of the body of knowledge available on pollution in the North Sea, and revealed that many aspects of marine pollution cannot be considered in world-wide terms but must ultimately be dealt with on the basis of regional physicochemical and biological realities.

The Symposium has finally demonstrated that the evaluation of the presumptive consequences of water pollution requires a variety of approaches, criteria and techni- 
ques. The two major categories of approaches are: investigations in the labor a tory and in the sea.

In the laboratory, the fastest but also vaguest evaluation can be obtained by mortality tests. More sensitive, and more important for assessing the presumptive consequences, is the study of long-term, sublethal effects employing criteria such as rates and efficiencies of metabolism, growth and reproduction. Detailed analyses require experiments conducted over one or more generation(s), as well as performance tests under a variety of additional stresses such as starvation and extreme conditions of temperature, salinity, $\mathrm{O}_{2}$ or $\mathrm{CO}_{2}$ partial pressures, etc. - employing different (stenoplastic) ecological and morphological representatives of the natural eco-system under consideration. At present, "permissible" concentration limits of pollutants are usually expressed as acutely measured responses. There is urgent need for studies which take into consideration the capacity of the organism in question to acclimate to different levels of pollutional stress.

Evaluation of pollution effects on interspecific relations requires multi-species cultures and "artificial" or "simplified eco-systems" (similar to the "microcosm technique" reported here by Drs. HuEck \& ADEMA), consisting of important food chain members, e. g., phytoplankton, zooplankton and fish. Suitable representatives of the food chain could be maintained in separated but interconnected compartments through which the test mixture of pollutants flows under defined conditions, maintaining its desired concentration and physico-chemical activity. Such artificial eco-systems would also allow the study of certain aspects of bio-accumulation and bio-degradation of pollutants. The main problem in conducting pollution experiments on artificial marine eco-systems, is the fact that we have not yet learned how to breed even the most important members of a system under controlled conditions in the laboratory. Hence, one of our major objectives in marine pollution studies must be to increase our present capacity to rear and breed marine organisms.

Even though laboratory studies of the kind mentioned above provide useful tools for the appraisal and critical analysis of the biological consequences of pollutants, the question remains to be answered as to what extent the results obtained under laboratory conditions are immediately extendible to the situation in situ, and to what degree they warrant safe predictions. It seems, therefore, that we must - in addition to the various laboratory approaches mentioned - conduct experiments in large containers, separated small sea areas and, most important, in the sea itself. We must "test pollute" suitable areas or bodies of water and study the physico-chemical and biological consequences in situ, employing skin divers, ships, underwater television and other appropriate technological underwater equipment.

Both in the laboratory and in the sea, the most important end points to be determined are those concentrations of pollution mixtures - effective for long periods of time under a given set of environmental conditions - which limit or alter rates and efficiencies of reproduction and affect the dynamic equilibrium of coexistence between populations of the bio-system under consideration. The individual itself counts little in nature, unless it partakes in the reproductive activities of the population and exerts influence on coexisting forms of life.

An aspect of water pollution, which has hardly been mentioned during this Sym- 
posium, concerns physical and chemical interactions of the different components of a given mixture of polluting substances. Certainly, some interactions may modify both the chemical identity and the effects of pollutants on biological systems. Further, more attention must be paid to the fate of pollutants after they have been released into the sea (aggregation, dispersion, bio-modification). As an historical event, marine pollution is becoming a world-wide problem. As an object for scientific study, however, it must be visualised in immediate context with the individual local situation (geographic area; geomorphology; physico-chemical properties of the water; local microbial, plant and animal life; historic aspects; other previous or concomittant sources of pollution; and other kinds of additional environmental stress).

The primary goal in water pollution research is a sound scientific controlling and forecasting capacity. We want to know how mudh of the pollutants in question can a given area or water body receive per unit of time without detrimental long term effects on its living and non-living components.

Considering the immediate future of the North Sea, it is felt that fast and responsible measures must be taken. It is likely that someone will say to us "alright, you had a Symposium on North Sea pollution; but what did you actually do about it?" The other evening we had an ad hoc-committee-discussion under the chairmanship of Dr. KORRINGA; it was suggested that I draft some recommendations summarizing the various points discussed. This draft was amended and later approved by Drs. P. KorRINGA (Director, Rijksinstituut voor Visserijonderzoek, Ijmuiden, The Netherlands), M. Ruivo (Chief, Marine Biology and Environment Branch, Fishery Resources and Exploitation Division of FAO, Rome, Italy), A. C. Srmpson (Director, Fisheries Laboratory, Burnham-on-Crouch, Essex, England) and G. Tomczak (Deutsches Hydrographisches Institut, Hamburg, Germany). I have been asked to read it to the general audience and to ask for your approval. It is intended to submit these recommendations to the president of the International Council for the Exploration of the Sea.

\section{RECOMMENDATIONS \\ of}

the participants of the

International Symposium: "Biological and hydrographical problems of water pollution in the North Sea and adjacent waters", held on Helgoland, West Germany, September 19 through 22, 1967.

Prepared by Drs. O. Kinne, M. Rurvo, A. C. Simpson, G. Tomczak, P. Korringa, and approved by the general audience.

Under the sponsorship of the Biologische Anstalt Helgoland, an International Symposium on "Biological and hydrographical problems of water pollution in the North Sea and adjacent waters" was held from September 19 to 22, 1967. It was attended by about 200 scientists from 13 different countries.

From the scientific papers presented and from the discussions which took place at the Symposium it became evident that pollution of the North Sea and adjacent waters has become a most important problem for modern mankind, and one that requires concerted action to stop or to reduce present trends and to avoid detrimental irreversible changes in habitats and marine communities.

The North Sea is especially endangered for a number of reasons of which the following are among the most important: 
(a) it is shallow having an average water depth of $20 \mathrm{~m}$ throughout its southernmost part

(b) its water exchange with the Atlantic is restricted

(c) it is surrounded by highly industrialized, heavily populated, nations

(d) it contains rich fishing grounds, and its inshore waters serve as nursing, as well as spawning areas for many fishes and other species of commercial value

(e) it serves for hundreds of thousands, if not millions, of people as a recreation area.

For these reasons the participants of the International Symposium recommend that:

(1) Researd be encouraged into all aspects of marine pollution.

(2) There should be greater interchange of information and co-ordination of research in this field.

(3) Government agencies of different countries adjoining this area should be asked to co-ordinate their research and administrative efforts with a view to halting and reducing the adverse effects of pollution on the valuable international fisheries of the North Sea and adjacent waters.

To promote these aims the Symposium participants further recommend that: ICES be invited to:

(4) Take into account the scientific results presented and discussed at this International Symposium, and to be published in the "Helgoländer wissenschaftliche Meeresuntersuchungen" within the next seven months.

(5) Consider the formation of a committee to be concerned with pollution effects on the northwest European seaboard, and particularly, in the North Sea. The committee should stimulate and co-ordinate the production of such scientific information as is required by the responsible agencies to counteract and control pollution in the North Sea, including the preparation of a list of such substances which are known to be particularly harmful to marine life and human activities, and which, therefore, should be totally excluded from being dumped into the shallow parts of the North Sea. It is hoped that this committee will succeed in providing member governments with the scientific basis to take immediate measures against particularly harmful or potentially irreversible pollution effects in the North Sea, even before the urgently required formal international conventions are established.

The Symposium participants, finally, welcome the arrangements being made by FAO to convene a World Conference on marine pollution effects of fishery resources and fishing operations, scheduled for 1969 . They recommend that all possible assistance be given to FAO by governments and scientists concerned with marine pollution in order to facilitate the most successful use of this international forum. to:

The Symposium participants note with satisfaction the plans of FAO and UNESCO/IOC

(1) encourage and co-ordinate scientific research

(2) facilitate exchange and dissemination of research and technological experiences, as well as the training of experts in the field of marine pollution.

(Of the Symposium participants present, one withheld his vote, all others approved the recommendations; these were forwarded to the president of ICES on September 26, 1967).

Dear colleagues and friends,

Please accept my sincere thanks for contributing to this Symposium. I would like to express my special gratitude to all speakers, chairmen and contributors to the discussions. Drs. Gunkel, MAnN and Tomczak have assisted and advised me in regard to 
the preparation of this Symposium, and many members of the Biologische Anstalt Helgoland have helped with great enthusiasm to organise this meeting, especially Drs. Kornmann, Gunkel, and Bulnheim as well as Frau Wurl, Frau Heinemann, Mrs. Christian, Miss Farmer, Fräulein Bosse and Herr Marschall. The community of Helgoland and, of course, our Ministry, have supported us wholeheartedly. I am very grateful for all this assistance and support.

It is my sincere hope that this Symposium may contribute to our present knowledge on marine pollution in the North Sea and adjacent waters, and help to find solutions to this growing problem acceptable for governments, industry and science.

Thank you all again and a good trip home! I herewith close the International Symposium 1967. 